\title{
Gaziantep İlinde Güneş Enerjisi Potansiyelinin Analitik Hiyerarşi Süreci Yöntemi (AHP) İle Belirlenmesi
}

\author{
Determination of Solar Energy Potential in Gaziantep Province by Analytical Hierarchy \\ Process Method (AHP)
}

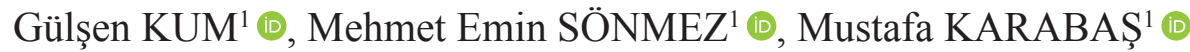

${ }^{1}$ Gaziantep Üniversitesi, Fen Edebiyat Fakültesi, Coğrafya Bölümü, Gaziantep,Türkiye

ORCID: G.K. 0000-0002-1617-1723; M.E.S. 0000-0003-2940-3308; M.K. 0000-0002-8680-7299

\section{öz}

Enerji talebinin sürekli arttığı günümüzde çevreci ve uzun ömürlü bir alternatif olarak yenilenebilir enerji kaynaklarının kullanımı hızla artmaktadır. Bu kaynakların en ucuz ve çevresel olanlarının başında ise güneş enerjisi gelmektedir. Türkiye de güneş enerjisi potansiyelin yüksek olduğu ve son zamanlarda enerji üretimi içinde güneş enerjisinin payının arttığı ülkelerden biridir. Türkiye'de güneş enerjisi potansiyelin en yüksek olduğu bölge ise Güneydoğu Anadolu Bölgesi'dir. Bölge genelinde ise hem enerji ihtiyacı hem de güneş enerjisi açısından potansiyeli yüksek olan illerin başında Gaziantep gelmektedir. Saha gerek yıllık toplam güneşlenme süresi, gerekse de yıllık toplam güneş radyasyonu miktarı bakımından Türkiye ortalamasının üzerinde bir potansiyele sahiptir.Türkiye'nin 6. büyük kenti olan Gaziantep aynı zamanda hem bölge hem de Ortadoğu sanayisinin lokomotifi durumunda olup, enerji ihtiyacı da diğer çevre illere göre de oldukça fazladır. Bu nedenle çalışma alanı olarak Gaziantep ili seçilmiş ve arazi kullanımı, trafolara uzaklık, ortalama sıcaklık, global güneşlenme durumu, ortalama güneşlenme süresi, eğim, bakı ve ana ulaşım güzergahlarına uzaklık parametreleri kullanılarak Gaziantep ilinin güneş enerjisi verimlilik haritası çizilmiştir. Bu haritanın oluşturulması için çok kriterli karar verme yöntemlerinden Analitik Hiyerarşi Yöntemi (AHY) kullanılmıştır. Çalışmanın sonucuna göre Gaziantep ili arazisinin yaklaşık \% 8'i güneş enerjisi verimliliği açısından çok uygun iken, \% 44'ü ise uygun durumdadır.

Anahtar kelimeler: Güneş Enerjisi, Analitik Hiyerarşi Yöntemi, Yenilenebilir Enerji

\section{ABSTRACT}

The use of renewable energy sources is rapidly increasing as a natural and long-lasting alternative along with the growing demand for energy supply today. One of the most inexpensive and environmentally-friendly resources is solar energy. Turkey is a country in which solar energy potential is quite high and where the share of solar energy in energy production has increased recently. The region with the highest solar energy potential in Turkey is the Southeastern Anatolian Region. The region has a potential above the average in Turkey in terms of annual sunshine duration and the total amount of annual solar radiation. As the sixth largest Turkish city, Gaziantep has a leading role in trade both within the province and with the Middle East, and so its energy need is significantly greater than those of the neighboring provinces. For this reason, Gaziantep was selected for the field of study and the solar energy efficiency map of Gaziantep province was drawn using parameters such as land use, distance to transformers, average temperature, global sunbathing condition, average sunbathing time, slope, aspect and distance to main transportation routes. In order to create this map, the Analytical Hierarchy Process (AHP) was used, which is a multi-criteria decision-making method. According to the results of the study, approximately $8 \%$ of the physical land of Gaziantep is classed as definitely ideal whereas $44 \%$ of the land is classed as ideal for solar energy efficiency.

Keywords: Solar energy, Analytical Hierarchy Process, renewable energy

Başvuru/Submitted: 04.09.2019 • Revizyon Talebi/Revision Requested: 16.10.2019 • Son Revizyon/Last Revision Received: 28.10 .2019 • Kabul/Accepted: 12.11.2019 • Online Yayın/Published Online: 06.12.2019 


\section{EXTENDED ABSTRACT}

Rapid economic growth and development around the world has also increased the need for energy resources. Today, approximately $81 \%$ of the world's energy needs are met by non-renewable fossil fuels - with adverse environmental impacts. In addition to the environmental impact of fossil fuels, the concentration of these sources in certain areas, the limited lifetime of reserves and high costs involved necessitate the use of different energy sources. This unfavorable situation has caused countries, such as Turkey, which imports a large percentage of its energy from abroad, to shift to environmentally-friendly and renewable energy sources such as wind, water, geothermal and solar. These sources, which are referred to as clean energy sources, have received great interest in recent years. Although global CO2 emissions from energy have increased, some countries have achieved significant reductions in electricity generation emissions, partly due to the use of renewable energy capacity.

Turkey has undertaken significant investments in terms of renewable energy sources in recent years. Hence, hydroelectric power plants meet about $32 \%$ of Turkey's electricity needs. The role of wind, which is another renewable energy source, has also increased in meeting the energy needs of Turkey. However, Turkey, which has a high solar-energy potential provided by the Mediterranean climate cannot fulfill its potential.

One of the areas that have the highest solar energy potential in Turkey is the Southeastern Anatolia Region. Throughout the region, Gaziantep is one of the provinces with high potential in terms of both energy needs and solar energy. The field has a potential above Turkey's average in terms of both total annual sunshine duration and total amount of solar radiation per year. The prolongation of daytime during the summer season causes the fields to receive more solar radiation, thus increasing the temperature values. In addition, factors such as low wind speed, relatively low air pollution, poor forest presence, low slope values of the land are also considered as positive factors in potential use. As the sixth largest Turkish city, it has a large industry, which plays a pivotal role in trade within the province and in the Middle East. In this respect, the energy needs of the city is significantly greater than those of the neighboring provinces. For this reason, Gaziantep was selected as a field of study and the solar energy efficiency map of Gaziantep province was drawn using parameters such as land use, distance to transformers, average temperature, global sunbathing condition, average sunbathing time, slope, aspect and distance to main transportation routes. In order to create this map, the Analytical Hierarchy Method (AHM) was used which provides both a high reliability and a wide range of use and which is also a multi-criteria decisionmaking method. According to the results of the study, approximately $8 \%$ of the physical land of Gaziantep is definitely ideal whereas $44 \%$ of the land is ideal for solar energy efficiency.

Thus, considering the land use and environmental sensitivity in the province of Gaziantep, it is determined that solar energy efficiency is quite high at $52 \%$ and this density is centered around the eastern parts of the city. On the other hand, while $32 \%$ of the land is not ideal for solar energy efficiency in the province, $16 \%$ is definitely not ideal. In the study, it is observed that the areas with low solar energy efficiency are particularly sensitive areas such as forest areas in the Amanos mountains and surrounding areas, water surfaces and surrounding areas and settlements with important irrigated agricultural areas. It is necessary to determine the resource potential for the production of Turkey's domestic alternative and renewable energy sources. Although solar energy has become a preferred source in recent years due to its minimal environmental impact as a clean, local and infinite source, it has disadvantages such as the cost of installation, its being dependent on climate (energy-producing capacity varies daily and seasonally) and its requirement for large construction areas.

Therefore, the geographic location of the switchboard should be taken into consideration. The Solar Energy Potential Atlas prepared in accordance with climatic only criterion for Turkey (GEPA) is inadequate in this regard and it is necessary to carry out local analyses taking all physical, human and economic factors into consideration. In addition, global climate change may lead to possible changes in the climate parameters of the selected site in terms of intensity, frequency and area, and may lead to differences in solar energy potential. Therefore, the effects of climate change need to be examined independently in such studies. 


\section{GÍRIŞ}

Bireylerden ülkelere her ölçekte yaşamı idame etmek için enerjiye ihtiyaç vardır. Gelişmiş ülkelerde evleri isıtmak ve aydınlatmak, araçları çalıştırmak ve sanayi üretimini sürdürmek için akıl almaz miktarlarda enerji harcanmaktadır (Mcleish, 2013). Özellikle ülkelerin hızlı ekonomik büyüme, kalkınma, nüfus artışı ve hayat standartlarının yükselmesi enerjiye olan talebi her geçen gün hızla artırmaktadır. Birincil enerji talebinin yaklaşık \% 81'nin karşılandığı (EIA, 2019) fosil kaynakların rezervlerinin sinırlı ve başta Orta Doğu olmak üzere belli alanlarda bulunması, dünya nüfusunun yaklaşı \% 18 'i olmasına rağmen \% 52'sinin OECD ülkeleri tarafindan tüketilmesi ve çıkarılan petrolün \% 70'nin OPEC ülkeleri tarafindan kontrol edilmesi (Kaiser, Unde, Kern, \& Jess, 2013, s. 489-490) ülkelerin bu kaynaklara alternatif olan enerji arayışlarını her zamankinden daha önemli hale getirmiştir. Yenilenebilir enerji kaynakları olarak tabir edilen bu kaynaklar, son y1llarda yoğun ilgi görmektedir. Her ne kadar küresel enerji kaynakl $\mathrm{CO}_{2}$ emisyonu artsa da, bazı ülkeler kısmen yenilenebilir enerji kapasitesinin kullanılması nedeniyle elektrik üretimi emisyonlarında önemli düşüşler sağlamıştır. Yenilenebilir Enerji Politikaları (REN21, 2018) verilerine göre, dünya genelinde yenilenebilir enerji yatırımları incelendiğinde, 2017'ye yönelik toplam yatırımın 279,8 milyar dolar olduğu ve bu alanda, özellikle gelişmiş ülkelerde yapılan önemli yatırımlar -başta Çin olmak üzere, ABD, Japonya, Hindistan ve Almanya- yenilenebilir enerji kullanımının avantajlarının dünya çapında kabul edildiğini göstermektedir. 2018'de ise dünyanın çeşitli yerlerinde yenilenebilir elektrik üretiminde birçok önemli adımlar atılmıştır. Örneğin; Avustralya, ilk kez yenilenebilir enerji kaynaklarını \%20'ye çıkarırken, Kosta Rika \%100 yenilenebilir enerji ile ülkeye 300 gün enerji sağlamıştır. 2019 yılının başlarında, ABD'de yenilenebilir elektrik üretimi, kömürle çalışan enerji üretimi seviyelerine yaklaşmış ve 2008-2018 yılları arasında yenilenebilir üretim neredeyse iki katına çıkmıştır. Avrupa'da, Portekiz, 2018 için elektrik tüketiminin yarısından fazlasını yenilenebilir kaynaklardan sağlamış, İngiltere, hem karada ( $\%$ $9,1)$ hem de denizde (\% 8) rüzgar enerjisi için üretim paylarında yıllık rekorlara imza atmıştır. İlk kez, AB rüzgar enerjisi ve güneş enerjisi ile yıllık elektriğin \% 15'inden fazlasını üretmiştir (REN21, 2018). Bu yönüyle gelecek yüzy1l, güneş ve onun türevleri ile diğer tükenmez ve temiz enerji kaynakları kullanımında atılım yapılacak bir yüzyıl olma görünümündedir (Kumbur, Özer, Özsoy ve Avc1, 2015). Gerçekten de yenilenebilir enerji kaynaklarının toplam kullanımı 1950 yılında \% 3 seviyelerinde iken 2018 yılı sonu itibariyle \% 11,5 seviyelerinde gerçekleşmiştir (EIA, 2019). Nitekim, Uluslararası Yenilenebilir
Enerji Ajans1 IRENA'nın (2018) yayınladığ1 rapora göre yenilenebilir kaynaklardan biri olan güneş enerjisi teknolojisi büyük bir sıçrama yapmaya hazır vaziyettedir. Raporda güneş enerjisinden elde edilmekte olan elektriğin günümüzde küresel elektrik üretiminin \%2'sine denk geldiği ifade edilirken, 2030'a kadar bu payın \%13 seviyesine çıkabileceği belirtilmiştir. Böyle bir büyüme ise şu anda dünyada $277 \mathrm{GW}$ seviyesinde olan kurulu kapasitenin 1.760-2.500 GW arasında bir yere yükseleceği anlamına gelmektedir.

Türkiye'nin ekonomik büyümesine, artan nüfusuna, sanayileşmesine ve yaşam koşullarının iyileşmesine paralel olarak enerji ihtiyacı hızla artmaktadır. Fosil yakıtlar açısından fakir sayılan Türkiye'nin enerji talebini yerli üretimle karşılama oranı 1990-2013 yılları arasında yaklaşı \%22 oranında azalırken, dışa bağımlılı̆̆ı aynı oranda yükselmiştir. Türkiye'de son on yılda doğal gazın elektrik üretimindeki payının \% 43-50 aralığında seyretmesi ithal doğal gaz kaynaklarına bağımlılığının ne kadar yüksek olduğunun açık bir kanıtıdır (Cebeci, 2017). Enerjide ithal fosil yakıtlı kaynaklara bağımlılığı yüksek olan Türkiye'de elektrik üretiminde kaynak çeşitliliğinin sağlanması, küresel ısınmayla mücadele ve fosil yakıtlarda dışa bağımlılığının azaltılması açısından yenilenebilir enerji kaynaklarından özellikle de yüksek güneş enerjisi potansiyelinin elektrik üretmek amacıyla değerlendirilmesi büyük önem arz etmektedir. Enerji ve Tabi Kaynaklar Bakanlığı'nın 2018 verilerine göre kurulu gücün \% 31,9'u hidrolik, \% 25,6's1 doğal gaz, \% 21,5'i kömür, \% 7,9'u rüzgâr, \% 5,7'si güneş, \% 1,4'ü jeotermal ve \% 5,9'u ise diğer kaynaklardan karşılanmaktadır. 2018 yılında işletmedeki güneş enerjisi santral sayısı 5.868 adet, 4.981.2 MW'1 lisanssiz, 81,8 MW da lisanslı olmak üzere toplamda güneş enerjisi gücü 5.063 MW'a ulaşmıştır. Ülkemizdeki toplam elektrik üretimi içerisindeki payı da 7.477.3 GWh ile \%2,5'a yükselmiştir (Enerji ve Tabi Kaynaklar Bakanlığı, 2018). Enerji ve Tabii Kaynaklar Bakanlığı'nın (2017) yayımladığı 'Dünya ve Türkiye Enerji ve Tabii Kaynaklar Görünümü” raporuna göre; 2014 yılı itibariyle $251.963 \mathrm{GWh}$ toplam elektrik üretimi içerisinde güneş enerjisi kaynaklı 17,4 GWh üretim (\%0,01 pay); 2016 y1lı itibariyle, $273.387 \mathrm{GWh}$ 'lık toplam üretimde 972 GWh’ye ulaşmıştır (\% 0,36 pay). 2018 yılında ise güneş enerjisi lisanssiz santrallerin toplam kurulu gücü ise $4.981 \mathrm{MW}$ 'a yükselmiştir. 2019 yılı 20 yıllık dönem için yıllık ortalama elektrik talebi artış oranı farklı senaryolara göre \%2,90-\%3,84 olarak hesaplanmaktadır. 2023 yılında 376 milyar kWh, 2039 yılında 613 milyar kWh seviyelerinde olacağı öngörülmektedir. $\mathrm{Bu}$ talebin karşılanmasında da yenilenebilir enerji kaynaklarının payının daha da artacağı öngörülmektedir (Enerji ve Tabii Kaynaklar Bakanlığı,2019). 
Enerji İşleri Genel Müdürlüğü (2019) 'nün hazırladığg İklimEnerji Raporu'na göre Türkiye'de elektrik ve doğalgaz taleplerinin iklim koşullarının etkisiyle özellikle kış aylarında ortalama seviyenin üzerinde gerçekleşeceği tahmin edilmektedir (EİGM, 2019). Bu durum Türkiye'nin geneli ve başta büyük şehirlerinde enerji ihtiyacının da her yıl giderek artacağını göstermektedir. Bu olumsuz durum, enerji ihtiyacının büyük bir yüzdesini dişarıdan temin eden Türkiye gibi ülkelerin çevreyle uyumlu ve aynı zamanda büyük ölçüde yenilenebilir olan rüzgâr, su, jeotermal ve güneş gibi enerji kaynaklarına yönelmesine neden olmuştur. Yenilenebilir enerji kaynakları açısından önemli bir potansiyele sahip olan Türkiye, son y1llarda bu alanda önemli yatırımlara da imza atmıştır. Nitekim hidroelektrik santralleri Türkiye'nin elektrik enerjisinin yaklaşık \%32'sini karşılamakta, ayrıca Türkiye'nin enerji ihtiyacını karşılamada diğer yenilenebilir enerji kaynakları olan rüzgâr ve güneşin de rolü gün geçtikçe artmaktadır. Yeryüzünün $45^{\circ}$ kuzey ve $45^{\circ}$ güney enlemleri arasında kalan sahalar güneş enerjisinden ekonomik olarak yararlanma olanağına sahiptir (Akova, 2003). Gerçekten de Türkiye'nin Karadeniz ile Marmara bölgeleri dışındaki diğer tüm alanlarda güneş enerjisi potansiyeli oldukça yüksektir (Enerji İşleri Genel Müdürlüğü, 2018). Güneş enerjisi 1şınım değeri $1460 \mathrm{kWh} / \mathrm{m}^{2}$-y1l ile en yüksek ve 2993 saat y1llık güneşlenme süresi ile fazla potansiyele sahip olan bölge ise Güneydoğu Anadolu'dur (Özgür, 2018, s.351-352). Bu veriler dünyanın en önemli güneş enerjisi üretici olan Almanya'nın çok çok üstünde olmasına rağmen minimum düzeyde bile kullanılamamaktadır.

Türkiye'de -özellikle son yıllarda- hatalı arazi kullanımının iklim üzerindeki etkileri (Boysen, vd. 2014) ve iklimdeki değişime bağlı olarak meydana gelen olumsuzlukların (Fu, Taive
Liao, 2016) çevre, ekonomi ve enerji başta olmak üzere tüm hayatı etkilemesi (Tol, 2018; Cronin, Anandarajah ve Dessens, 2018); arazi kullanımı, iklim değişimi, enerji ve su stratejilerinin bir arada yapılmasını zorunlu kılmaktadır (Dale, Efroymson ve Kline, 2011; Mpandeli, vd., 2018). Bu stratejilerin başarılı olabilmesi ve potansiyelin çevresel ve ekonomik etkiler de göz önünde bulundurularak en iyi şekilde değerlendirilebilmesi ancak jeoekolojik ve ekonomik planlamanın bir arada yapılması yani mekânın amaca en uygun şekilde planlaması ile mümkündür (Erinç, 1959; Ekinci ve Sönmez, 2006). Dolayısıyla bu çalışmada güneş enerjisi potansiyeli yüksek alanların belirlenmesinde çevresel ve ekolojik etkiler başta olmak üzere ekonomik açıdan verimlilik de göz önünde bulundurulmuştur. Bunun için çok kriterli karar verme yöntemlerinden, hem güvenirliliği yüksek hem de kullanım alanı çok geniş olan ve son yıllarda güneş enerjisi verimlilik haritalarının oluşturulmasında kullanılan Analitik Hiyerarşi Yöntemi (AHP) tercih edilmiştir (SánchezLozano, Teruel-Solano, Soto-Elvira ve García-Cascales, 2013; Uyan, 2013; Gašparovic ve Gašparovic, 2019; Doorga, Rughooputh ve Boojhawon, 2019).

\section{2. ÇALIȘMA ALANI}

Çalışmaya konu olan Gaziantep ili $37,38332^{\circ} \mathrm{K}$ enlemi ile $37,06622{ }^{\circ} \mathrm{D}$ boylamı arasında, ortalama $840 \mathrm{~m}$ yükseltiye sahiptir. Türkiye'nin nüfus bakımından 9. büyük ili olan Gaziantep, sanayi ve ticaret hacmi açısından genelde 6. sırada yer almakla beraber Türkiye'nin ilk on ilinden biridir. Kuzeyden Kahramanmaraş, kuzeybatı ve batıdan Osmaniye, batı ve güneybatıdan Hatay, güneyden Kilis ve Suriye, doğudan Şanlıurfa ve kuzey ile kuzeydoğudan Adıyaman iliyle komşu olan Gaziantep ili yaklaşık 7642 km² alana sahiptir (Şekil 1).

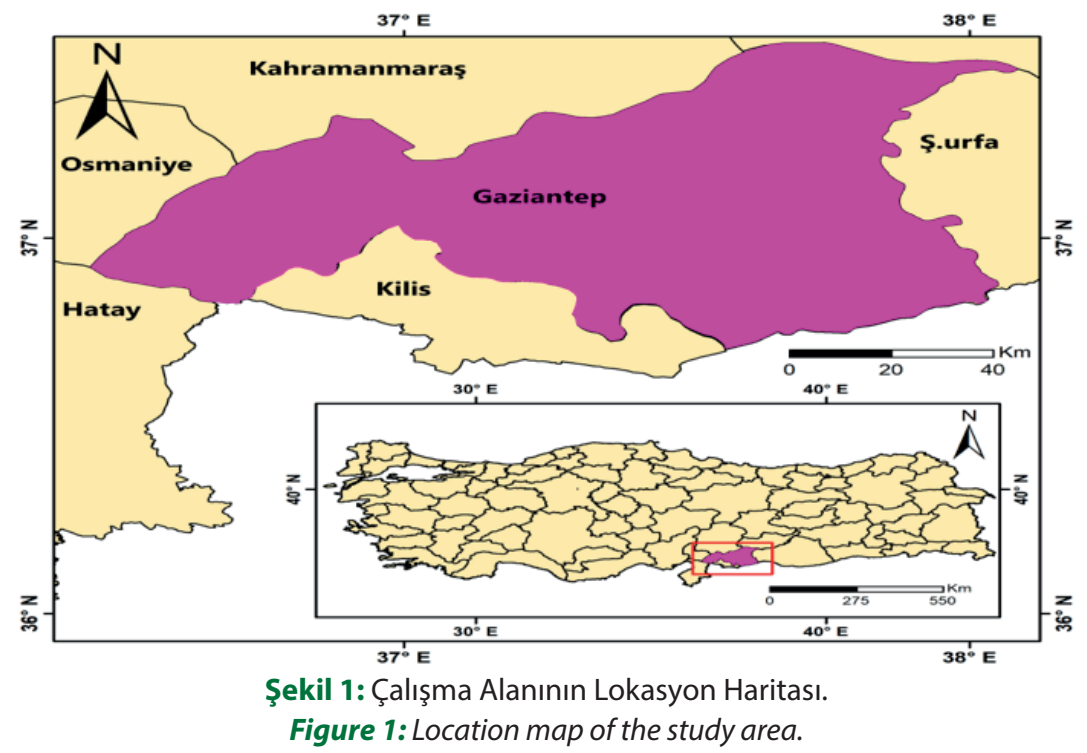


Sekiz ilçesi olan Gaziantep'in en önemli sanayi alanları merkez ilçeleri olan Şehitkâmil ve Şahinbey çevresinde yoğunlaşmıştır. $\mathrm{Bu}$ ilçeler önemli ölçüde sanayi ve ticaret alanları olarak karşımıza çıkarken, Nizip, İslâhiye, Oğuzeli, Nurdağı, Araban ve Karkamış ilçeleri zeytin, üzüm ve fistık başta olmak üzere önemli sebze, meyve ve tahıl üretim alanlarıdır. Bunlar arasında özellikle Nizip zeytin üretimi ve aynı zamanda zeytinyağı sanayisinin gelişmiş olduğu önemli ilçelerden biridir. Gerçekten de Türkiye'nin en önemli zeytinyağı üretim alanlarından biri olan Gaziantep aynı zamanda Türkiye'nin önde gelen Antep fistığı ve üzüm üreticisidir. Dolayısıyla Gaziantep Türkiye'nin önemli sanayi ve ticaret illerinden biri iken; aynı zamanda Türkiye'nin ekonomik değeri yüksek tarımsal ürünlerin yetiştirildiği illerin de başında gelmektedir. Bu nedenle Gaziantep ilinin enerji ihtiyacını karşılamada birincil kaynaklar dışında alternatiflere de yönelmesi gerekmektedir.

\section{AMAÇ VE YÖNTEM}

$\mathrm{Bu}$ çalışmanın amac1; Türkiye'nin 6 . büyük kenti olan Gaziantep'in, yüksek enerji ihtiyacına bir alternatif olarak, güneş enerjisi potansiyeline uygun sahalarını belirlemektir.

Güneş enerji santralleri için uygun yer seçimi konusunda kesin kurallar olmamakla birlikte faaliyet verimliliği ve çevresel etkiler karar verici tarafından göz önünde bulundurularak fiziki ve beşeri kriterler oluşturulabilmektedir. Bu çalışmada da uygun yer seçimi konusunda literatürden faydalanılarak bölgenin yerel iklim durumu, topografik yapı, arazi kullanım durumu, şebeke bağlantısı, enerji tüketim bölgelerine yakınlık ve erişilebilirlik gibi faktörler Gaziantep için öncelikli olarak belirlenmiş ve Gaziantep ilinin güneş enerjisi potansiyelinin belirlenmesindeki parametreler olarak kullanılmıştır. Bu bağlamda iklimsel veriler (ortalama sıcaklık, güneşlenme süresi ve radyasyon şiddeti) aylık ve uzun yıllık ortalamalar şeklinde Devlet Meteoroloji Genel Müdürlüğü arşivinden sağlanırken, ulaşım haritası Google Earth altlık olarak kullanılarak üretilmiş, topografik veriler (eğim ve bakı) 1/25.000 ölçekli Gaziantep topografya haritasından üretilmiş, arazi kullanımı haritası ise 2019 yılının Temmuz ayına ait Landsat OLI/TIRS bantları uzaktan algılama teknikleriyle sınıflandırmaya tabi tutularak oluşturulmuştur. Elde edilen bu veriler daha sonra ArcGIS 10.x ortaminda reclassify araç çubuğu kullanılarak, parametrelerin alt parametrelerine yeniden ağırlık değeri verilmiştir. Kendi içinde yeniden değerlendirilmeye tabi tutulan bu parametreler daha sonra 1'den 9'a kadar değişen değerlere sahip önem ölçeği vasıtasıyla kendi aralarında ikili karşılaştırmaları yapılmıştır (Tablo 1). Bu karşılaştırma matrisinden her bir parametrenin ağırlık değeri tespit edilmiş ve daha sonrasında rastercalculator araç çubuğu kullanılarak parametreler bir arada değerlendirilmiş ve sonuçta Gaziantep ilinin güneş verimlilik potansiyelini gösterir harita oluşturulmuştur (Şekil 2).

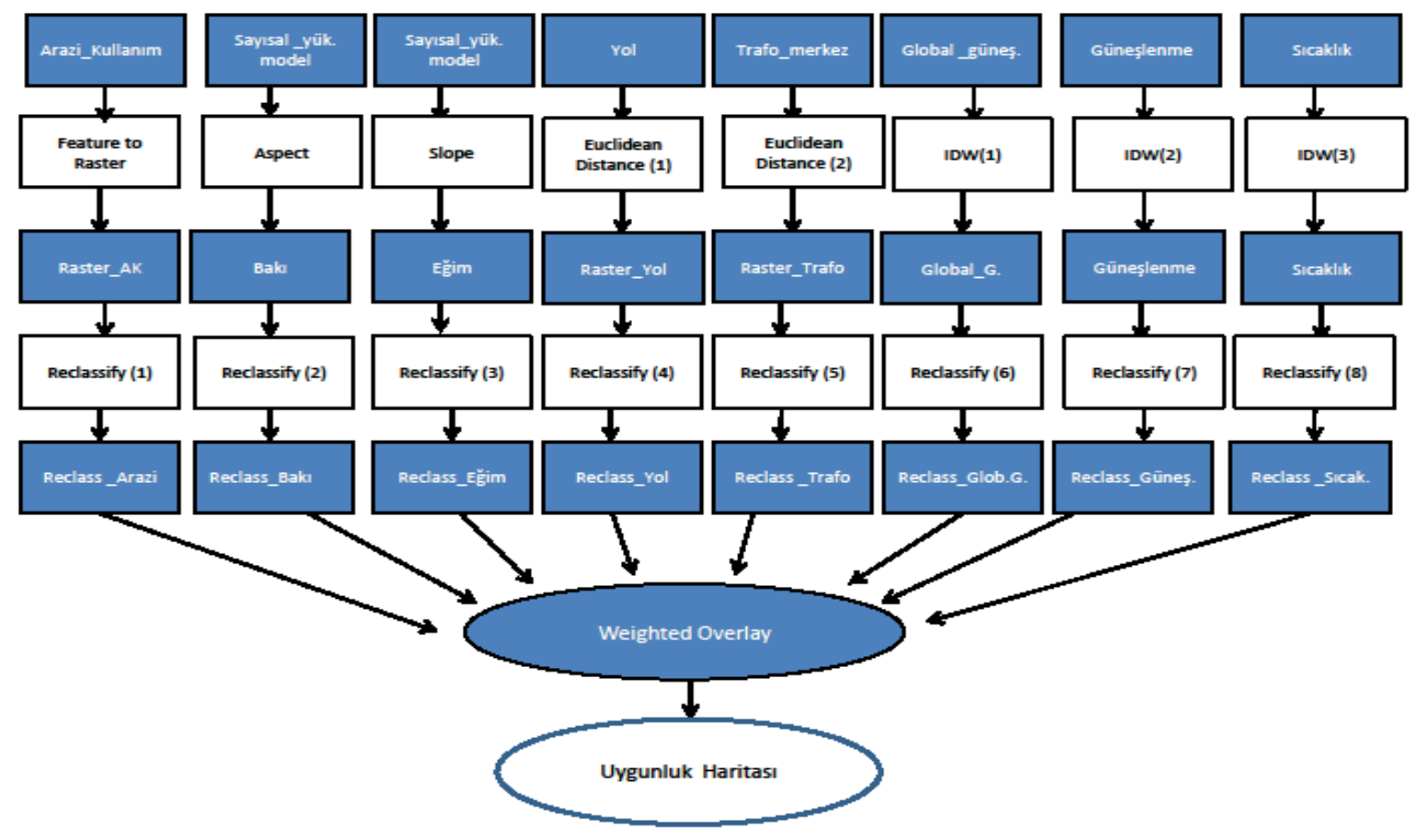

Şekil 2: Çok Kriterli Karar Verme Analizi Yönteminde İş Akış Süreci Şeması.

Figure 2: Workflow diagram for the multicriteria decision analysis. 
Çalışmada CBS destekli Çok Kriterli Karar Verme (ÇKKV) yöntemlerinden olan tanımlayıcı, nitel ve nicel kriterleri ikili karşıllaştırma ve puanlama ölçeği ile analiz eden Analitik Hiyerarşi Modeli (AHP) benimsenmiştir (Wind ve Saaty, 1980; Ünal, 2012; Saaty, 1990). Bu modelde kriterler arasında gerçekleştirilen ikili karşılaştırmalara dayalı olarak ikili karşılaştırmalar matrisi elde edilmekte, sonra bu kriterlerin ağıllıkları belirlenmektedir (Kazakis, Kougias ve Patsialis, 2015). AHP yöntemi ikili karşılaştırma yönteminde sadece temel parametreler değil, aynı zamanda alt parametrelerin de birbiri ile ilişkisini, belli bir hiyerarşik yapıda modelleyerek, tecrübe, birikim, anlayış ve sezgilerin de yorumlanmasına bilgisayar ortamında olanak sağlamaktadır (Özdemir ve Saaty, 2006; Ünal, 2012). Bu durum bu yöntemin daha esnek olmasını ve özellikle çevresel problemlerin sürekli arttığı ve çevresel duyarlılığın mutlak surette dikkate alınması gerektiği planlama çalışmalarda çok daha sağlıklı sonuçlar verebilir görünmektedir. Kısacası analitik hiyerarşi yöntemi, karar vermede birden çok parametrenin etkili olduğu problemlerin Tablo 1'de verilmiş olan ikili karşılaştırma matrisi ölçeğindeki önem değerleri ile ikili karşılaştırmalara indirgeyen ve buradan sonuca ulaşmaya çalışan ÇKKV yöntemlerinden bir tanesidir. Güneş enerjisi verimliliğini doğal ve beşeri çevreye ait birçok parametre belirlediğinden bu çalışmada da ÇKKV yöntemi olan AHP tercih edilmiştir.
Tablo 1: AHP İkili Karşılaştırma Ölçeği (Saaty, 2008, s. 86).

Table 1: AHP Scale of binary comparison (Saaty, 2008, s. 86).

\begin{tabular}{ll}
\hline Önem Değerleri & Değer Tanımları \\
\hline $\mathbf{1}$ & Eşit Önemde \\
$\mathbf{3}$ & Biraz Daha Önemli (Az Üstünlük) \\
$\mathbf{5}$ & Oldukça Önemli (Fazla Üstünlük) \\
$\mathbf{7}$ & Çok Önemli (Çok Üstünlük) \\
$\mathbf{9}$ & Son Derece Önemli (Kesin Üstünlük) \\
$\mathbf{2 , 4 , 6}$ ve 8 & Ara Değerler (Uzlaşma Değerleri) \\
\hline
\end{tabular}

\subsection{Güneș Enerjisi verimliliğinde Rol Oynayan Parametreler}

\subsubsection{Stcaklık, Güneşlenme Süresi ve Radyasyon}

Köppen- Geiger'in iklim sinıflandırmasına göre (Kottek, 2006) Gaziantep ili 1lıman iklimlerden (C); kışı 1lık, yazı çok sıcak ve kurak iklim-Akdeniz İklimi (Csa) sınıfina girmektedir. İl genelinde ortalama güneşlenme süresinin 200 günden fazla olduğu ve özellikle doğu ile güney kesimlerinde bu değerin 220 saatin üzerine çıktığı görülmektedir (Şekil 3). Güneş panelleri için ortam sıcaklığının çok yüksek olması verimin \%100 olmaması dolayısıyla enerjinin bir kısmı elektrik enerjisine dönüşürken bir kısmının da 1sı enerjisine dönüşümüne neden olur. Bu da güneş enerjisi üretiminde verim kaybına neden olur (Keçel \& Yavuzcan, 2008; Çarkıt, 2016). Gaziantep aylık
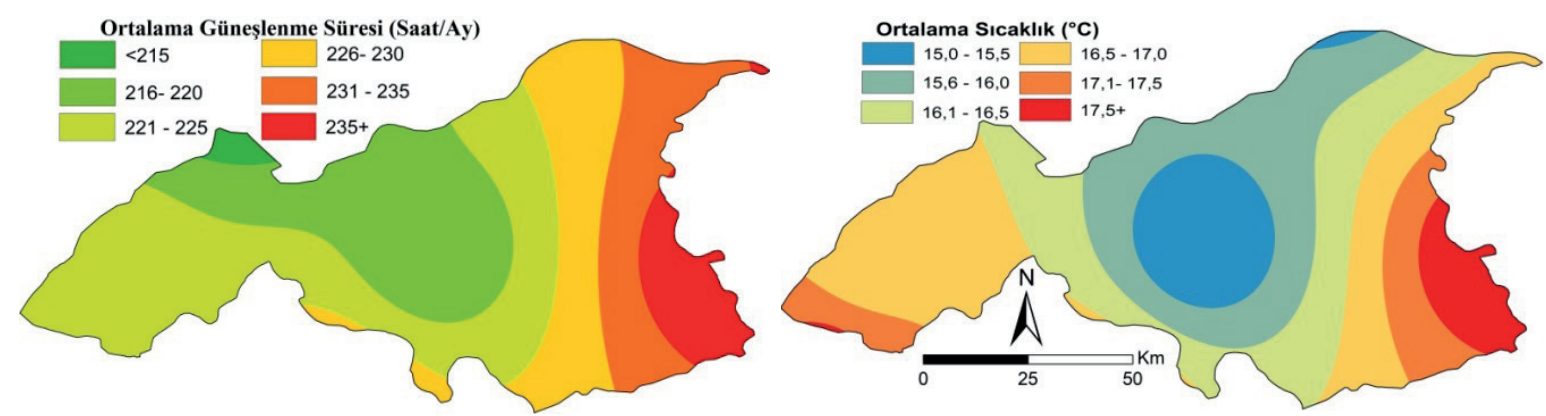

Şekil 3: Gaziantep Illinin Aylık Güneşlenme Süresi (solda) ve Ortalama Sıcaklık Değerleri (sağda). Figure 3: Monthly sunshine duration (left) and average temperature values (right) of Gaziantep.

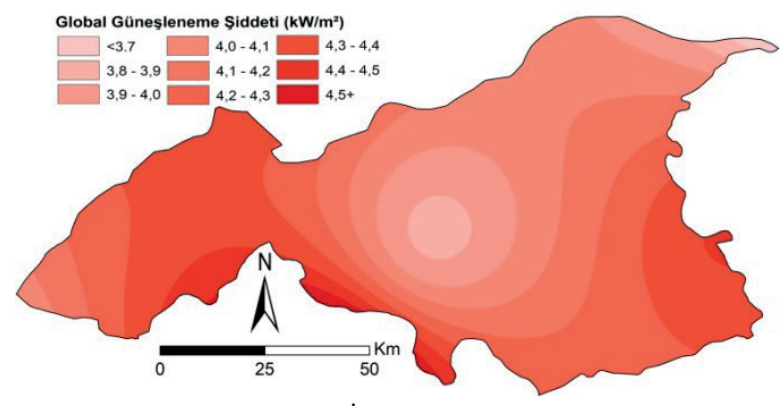

Şekil 4: Gaziantep İlinin Güneşlenme Şiddeti.

Figure 4: Solar radiation intensity of Gaziantep. 


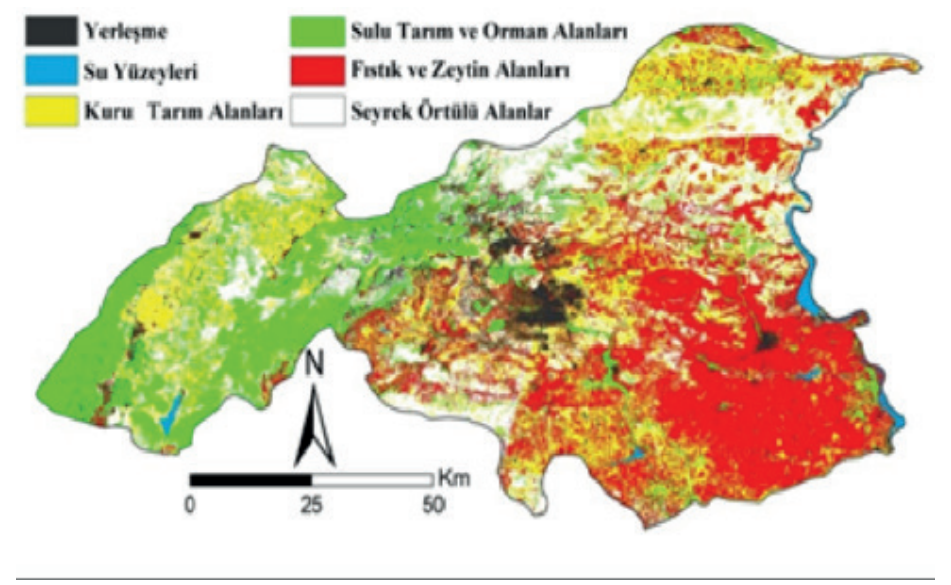

Şekil 5: Gaziantep İlinin Arazi Kullanımı Haritası.

Figure 5: Land use map of Gaziantep province.

ortalama sıcaklık değerleri $3.3-27.9^{\circ} \mathrm{C}$ arasında değişmektedir. Yıllık sıcaklık değerleri ise il merkezinde $15{ }^{\circ} \mathrm{C}$ civarında olup, doğu-batı ve kuzey-güney yönünde artış göstererek $18{ }^{\circ} \mathrm{C}^{\prime} \mathrm{ye}$ yaklaşmaktadır (Şekil 3). İlin güneşlenme şiddeti de sıcaklık ve güneşli gün ve saat sayısına bağlı olarak il merkezinden çevreye doğru artış göstermekte, özellikle doğu ve güney kesimlerde maksimum seviyeye çıkmaktadır (Şekil 4). Yıl içerisinde bulutlu gün sayısının oldukça düşük değerler göstermesi $(0,5$ 5,3 gün/yıl) güneş enerjisi kurulumu için avantaj sağlamaktadır. Rüzgâr değerlerine bakıldığında batılı rüzgârların hâkim olduğu, yılda ortalama 9,1 km/saat hiz ile santral kurulumuna olumsuz bir etkinin söz konusu olmadığı belirlenmiştir. Çalışmada aylık ortalama güneşlenme süresi, yıllık ortalama sıcaklık değerleri ve global güneşlenme şiddeti Gaziantep ilinin güneş enerjisi potansiyelinin belirlenmesinde kullanılan iklim parametreleridir. Çalışmada aylık güneşlenme süresi ve ortalama sıcaklıkların il genelinde birbirine yakın oluşu alt kriter ve genel olarak CBS ağırlık değerinin düşük olmasında etkili olmuştur.

\subsubsection{Arazi Kullanımı}

Santrallerinin yer seçiminde verimliliği etkileyen temel faktörlerin başında bitki örtüsü, yerleşmeler, sulak alanlar ile tarımsal değeri yüksek alanlar gelmektedir. Bu nedenle arazi kullanımı ve arazi örtüsü güneş enerjisi potansiyelini büyük ölçüde sınırlandırmaktadır. Zaten santrallerin kurulacağı alanlar yangın riski ve gölge etkisi sebebiyle vejetasyondan yoksun/ arındırılmış olmalıdır. Ayrıca biyoçeşitlilik açısından son derece önemli olan sulak alanlar ve ekonomik açıdan önem arz eden verimli tarım arazileri ile şehirler de güneş enerjisi santrallerinin kurulmasının önündeki önemli engellerdir. Kaldı ki son yıllarda hatalı arazi kullanımının yarattığı etkiler, gıda fiyatlarındaki artışlar ile iklim değişimi bu parametrelerin önemini daha da arttırmaktadır. Bu nedenle bu çalışmada arazi kullanımı hem alt parametreler açısından hem de genel içindeki CBS ağırlık değeri en yüksek parametre olarak belirlenmiştir. Bununla birlikte şehir merkezi daha çok çıplak sahalar ve yer yer ağaçlandırılmış alanlar ile step sahalarından oluşur. Ormanlık alanlar sahanın daha çok batı ve kuzey kesiminde parçalar halinde görülmektedir (Şekil 5).

\subsection{3. Ĕgim ve Bakı}

Santrallerin yer seçiminde optimum topografik şartlar düz ve düze yakın sahalardır. Bu bakımdan literatüre göre eğimin $1-5^{\circ}$ arasında olması tercih edilir. Yine bak1 nedeniyle güneşlenme koşullarının uygun olduğu güney yamaçlar kurulum için uygun koşullar sağlarlar. Gaziantep iline baktığımızda özellikle plato sahasının büyük ölçüde düz veya düze yakın yani güneş enerjisi santralinin kurulumuna uygun eğim değerlerine sahip olduğu görülmektedir. Sadece ilin batısındaki yüksek Amanos kütlesi ile yine plato ile İslâhiye depresyonunu ayıran Sof dağları ve çevresinde eğim değerleri yüksektir (Şekil 6). Dolayısıyla eğim güneş enerjisi santralleri için yer seçiminde önemli iken, Gaziantep ili özelinde fazla önem arz etmemektedir.

Çalışmadaki diğer önemli topografik parametrelerden diğeri ise bakıdır. Gaziantep ili genelinde özellikle plato sahasının büyük ölçüde düz ve düze yakın olması bakının etkisini de önemli ölçüde azaltmaktadır. Bununla birlikte yükseltinin de Gaziantep'te güneyden kuzeye doğru artması ildeki arazilerin büyük kısmının güney yönlü olmasında etkili olmuştur. Böylece eğim parametresinde olduğu gibi bakı faktörü de ağırlık değeri daha düşük seviyelerde olmuştur (Şekil 6). 


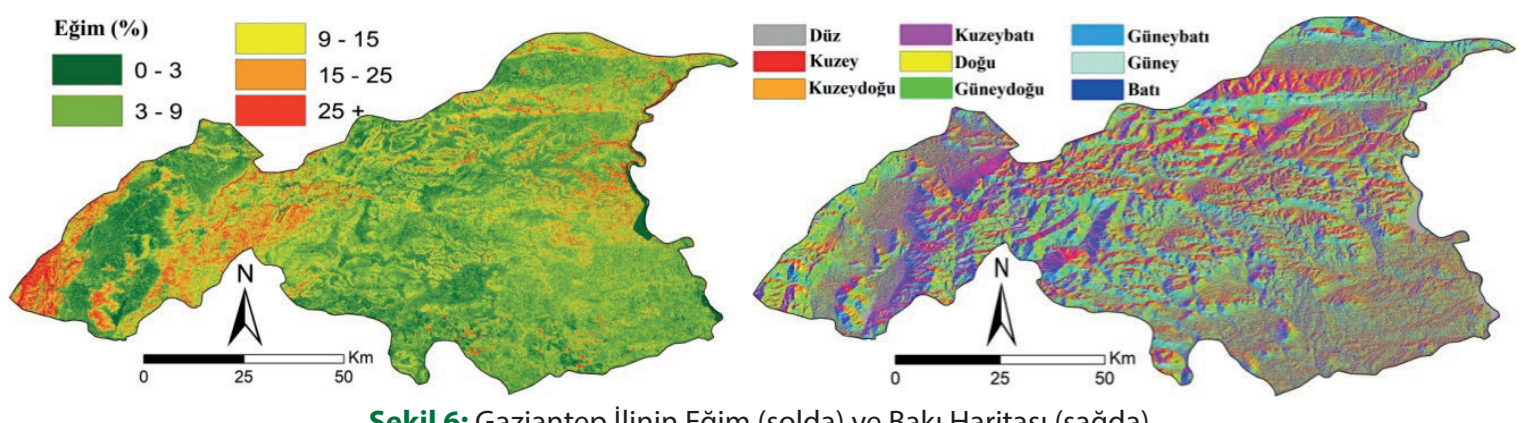

Şekil 6: Gaziantep İlinin Eğim (solda) ve Bakı Haritası (sağda).

Figure 6: Slope (left) and aspect map of Gaziantep province (right).

\subsubsection{Trafo ve ulaşım hatlarına uzaklık}

Büyük ölçekli santrallerin ulusal şebeke ağına $10 \mathrm{~km}$.den daha uzak mesafede olması tercih edilmemektedir. Dolayısıyla güneş enerjisi santrali yer seçiminde belirleyici olan bir diğer kriter ise trafolara olan mesafesidir. Üretilen enerjinin uzak tüketim bölgelere iletilmesi enerji kaybına neden olduğundan ve iletimdeki kayıp oranı verimliliği düşürdüğünden (Aydın, 2009) bu parametre ekonomik anlamda büyük önem arz etmektedir. Çalışma sahasında önemli enerji depolama hatlarının düzensiz dağılmış olması, trafolara yakınlık faktörünün önemini artırmaktadır (Şekil 7). Dolayısıyla trafolara yakınlık parametresinin ağırlık değeri de yüksek değer göstermiştir.

Ulaşım hatlarına uzaklık ekonomik açıdan önemli bir parametre olmakla beraber Gaziantep ilinde önemli bir sorun teşkil etmemektedir. Gaziantep ilinde belirli ormanlık ve sarp alanlar dişında (ki buralar güneş enerjisi üretimine uygun değildir) ulaşım ağı son derece gelişmiştir (Şekil 7). Dolayısıyla ulaşımın il genelinde güneş enerjisi verimliliği üzerindeki önemi oldukça düşüktür. Çalışmada güneş enerjisi verimliliğini etkileyen parametreler ve bunların alt sinifları Tablo 2'de gösterilmiştir. Çalışmadaki parametrelerin alt sınıfları da çalışma içindeki önem derecelerine göre ArcGIS 10.x yazılımındaki "Spatial Analyst Tools" modülündeki"Reclassify" araç çubuğu vasıtasıyla yeniden sınıflandırılmış ve böylece alt parametrelerin çalışma içinde ağırlık değerleri atanmıştır (Tablo 2). Bu alt parametreler çalışmada güneş enerjisi verimlilik haritasının oluşturulmasında önemli rol oynamıştır.

AHP birçok farklı çalışmada (Güney ve Turoğlu, 2018; Uyan, 2017; Alami Merrouni, Elwali Elalaoui, Mezrhab, Mezrhab ve Ghennioui, 2018) uygulandığı şekliyle bu çalışmada da arazi kullanımı, bakı, eğim, ortalama sıcaklık, güneşlenme süresi, radyasyon derecesi, trafolara ve ulaşım hatlarına uzaklık parametreleri dikkate alınarak uygulanmıştır. Tablo 3 'te gösterildiği gibi parametreler ikili karşılaştırmalar yoluyla birbirleriyle karşılaştırılmış ve ağırlık değerleri atanmıştır. Bu ağırlık değerleri ArcGIS 10.x yazılımındaki "Spatial Analyst Tools" modülündeki "Raster Calculator"yardımıyla analiz edilmiş ve böylece Gaziantep ilinin güneş enerjisi verimlilik haritası elde edilmiş̧ir. Son olarak elde edilen harita eşit aralık yöntemiyle kesinlikle uygun değil, uygun değil, uygun, çok uygun kategorilerinde önem ölçeğine göre sınıflandırılmıştır (Şekil 8).
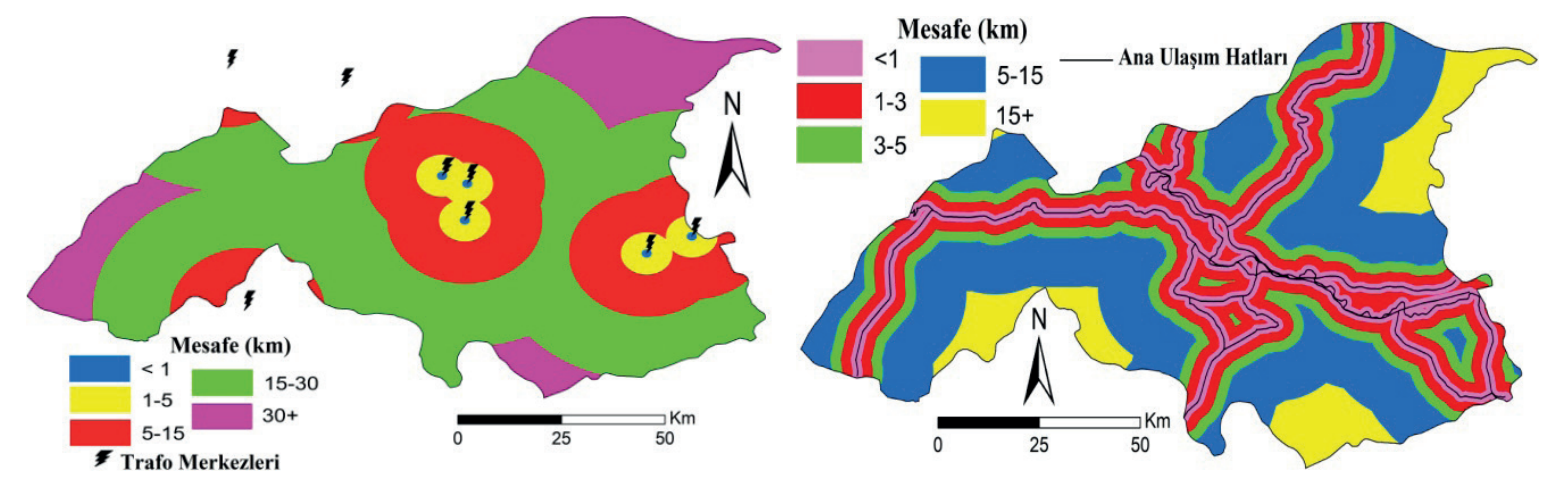

Şekil 7: Trafolara (solda) ve Mevcut Ulaşım Hatlarına (sağda) Uzaklık Haritaları.

Figure 7: Map of distance to transformers (left) and existing transport lines (right). 
Tablo 2: Parametre ve Alt Parametrelerin Ağırlıklı Sınıflandırılması. Table 2: Weighted classification of parameters and sub-parameters.

\begin{tabular}{|c|c|c|}
\hline Parametreler & Alt Parametreler & Ağırlık \\
\hline \multirow{6}{*}{ Arazi Kullanımı } & Şehirsel Alanlar & 0,088 \\
\hline & Su Yüzeyi & 0,054 \\
\hline & Kuru Tarım Alanları & 0,264 \\
\hline & Orman ve Sulu Tarım Alanları & 0,033 \\
\hline & Fıstık ve Zeytin Tarım Alanları & 0,143 \\
\hline & Seyrek Örtülü Alanlar & 0,417 \\
\hline \multirow{9}{*}{ Bakı } & Düz & 0,304 \\
\hline & Kuzey & 0,020 \\
\hline & Kuzeydoğu & 0,054 \\
\hline & Kuzeybatı & 0,050 \\
\hline & Doğu & 0,073 \\
\hline & Güneydoğu & 0,106 \\
\hline & Güneybatı & 0,113 \\
\hline & Güney & 0,200 \\
\hline & Batı & 0,079 \\
\hline \multirow{9}{*}{ Global Güneşlenme } & $<3,7-3,8$ & 0,018 \\
\hline & $3,8-3,9$ & 0,057 \\
\hline & $3,9-4,0$ & 0,038 \\
\hline & $4,0-4,1$ & 0,040 \\
\hline & $4,1-4,2$ & 0,057 \\
\hline & $4,2-4,3$ & 0,111 \\
\hline & $4,3-4,4$ & 0,116 \\
\hline & $4,4-4,5$ & 0,151 \\
\hline & $4,5-4,5+$ & 0,303 \\
\hline \multirow{6}{*}{ Güneşlenme Süresi } & $215+$ & 0,032 \\
\hline & $216-220$ & 0,051 \\
\hline & $221-225$ & 0,084 \\
\hline & $226-230$ & 0,126 \\
\hline & $231-225$ & 0,243 \\
\hline & $225+$ & 0,466 \\
\hline \multirow{6}{*}{ Ortalama Sıcaklık } & $15,0-15,5$ & 0,032 \\
\hline & $15,6-16,0$ & 0,054 \\
\hline & $16,1-16,5$ & 0,090 \\
\hline & $16,5-17,0$ & 0,153 \\
\hline & $17,1-17,5$ & 0,186 \\
\hline & $17,5+$ & 0,415 \\
\hline \multirow{5}{*}{ Eğim } & $0-3$ & 0,510 \\
\hline & $3-5$ & 0,262 \\
\hline & $9-15$ & 0,129 \\
\hline & $15-25$ & 0,063 \\
\hline & $25+$ & 0,023 \\
\hline \multirow{5}{*}{ Trafo Merkezlerine Yakınlık } & $<1$ & 0,513 \\
\hline & $1-5$ & 0,262 \\
\hline & $5-15$ & 0,129 \\
\hline & $15-30$ & 0,063 \\
\hline & $30+$ & 0,033 \\
\hline \multirow{5}{*}{ Ulaşım Ağlarına Yakınlık } & $>1$ & 0,524 \\
\hline & $1-3$ & 0,243 \\
\hline & $3-5$ & 0,122 \\
\hline & $5-15$ & 0,077 \\
\hline & $15+$ & 0,034 \\
\hline
\end{tabular}

\section{BULGULAR}

Çalışmada Türkiye'nin ve Ortadoğu'nun önde gelen sanayi merkezlerinden biri olan Gaziantep şehrinin enerji ihtiyacını karşılamada potansiyeli oldukça yüksek olan güneş enerjisi için uygun alanları belirlemek amacıyla ÇKKV yöntemlerinden biri olan AHP kullanılmış ve Gaziantep ilinin güneş enerjisi verimlilik haritası elde edilmiştir (Şekil 4).

Bu haritaya göre Gaziantep ilinde düşük eğimli, düz, güneye bakan (güney, güneydoğu, güneybatı) konumda ve seyrek bitki örtüsü ile kaplı alanlar ile trafolara yakın ve kuru tarım sahaları güneş enerjisi santralleri için çok uygun alanları oluşturmuştur. Buna göre çalışma sahasında güneş enerjisi verimliliği için çok uygun alanların $\left(593,1 \mathrm{~km}^{2}\right)$ oranı toplam arazinin yaklaşık \% 8 'dir. Çalışmada il genelinde güneş enerjisi verimliliği açısından uygun olan alanın $\left(3389,5 \mathrm{~km}^{2}\right)$ toplam alana oranı ise \% 44 'tür (Tablo 4). Böylece Gaziantep ilinde arazi kullanımı ve çevresel duyarlılık da göz önünde bulundurulduğunda güneş enerjisi verimliliğinin \% 52 ile oldukça yüksek olduğu ve bu potansiyelin nispeten şehrin doğu kesimlerinde yoğunlaştığı belirlenmiştir. Buna karşılık il genelinde arazinin yaklaşık \% 32'si güneş enerjisi verimliliği açısından uygun değilken, \% 16'sı ise kesinlikle uygun değildir.

Tablo 4: Gaziantep İlinin Güneş Enerjisi Verimlilik Durumu Table 4: Solar power efficiency status of Gaziantep Province

\begin{tabular}{cc}
\hline Uygunluk durumu & Alan $\left.\mathbf{( k m}^{2}\right)$ \\
\hline Çok uygun & 593,1 \\
Uygun & 3389,5 \\
Uygun Değil & 2469,7 \\
Kesinlikle uygun değil & 1189,7 \\
\hline
\end{tabular}

Çalışmada güneş enerjisi verimliliğinin düşük olduğu alanlar ise özellikle Amanos dağları ve çevresindeki ormanlık alanlar, su yüzeyleri ve çevresi gibi duyarlılık isteyen alanlar ile önemli sulu tarım alanları ile yerleşmeler olduğu görülmektedir.

Tablo 3: Parametreler Arası Karşılaştırma Matrisi

Table 3: Pairwise comparison matrix for parameters

\begin{tabular}{|c|c|c|c|c|c|c|c|c|c|}
\hline & Arazi Kul. & Bakı & Eğim & Ulaş. Uz. & Trafo Uz. & Global Gün. & Güneş Sür. & Ort. Sic. & Ağırlık Değeri \\
\hline Arazi Kullanımı & 1 & 3 & 7 & 9 & 2 & 3 & 4 & 4 & 0,314 \\
\hline Bakı & $1 / 3$ & 1 & 5 & 2 & $1 / 2$ & 1 & 2 & 2 & 0116 \\
\hline Eğim & $1 / 7$ & $1 / 5$ & 1 & 1 & $1 / 5$ & $1 / 3$ & $1 / 2$ & $1 / 2$ & 0,035 \\
\hline Ulaşım ağına uzaklık & $1 / 9$ & $1 / 5$ & 1 & 1 & $1 / 5$ & $1 / 3$ & $1 / 2$ & $1 / 2$ & 0,038 \\
\hline Trafolara uzaklık & $1 / 2$ & 2 & 5 & 5 & 1 & 5 & 6 & 6 & 0,274 \\
\hline Global Güneşlenme & $1 / 3$ & 1 & 3 & 3 & $1 / 5$ & 1 & 2 & 2 & 0,102 \\
\hline Güneş Süresi & $1 / 4$ & $1 / 2$ & 2 & 2 & $1 / 7$ & $1 / 2$ & 1 & 1 & 0,061 \\
\hline Ortalama sıcaklık & $1 / 4$ & $1 / 2$ & 2 & 2 & $1 / 7$ & $1 / 2$ & 1 & 1 & 0,061 \\
\hline
\end{tabular}




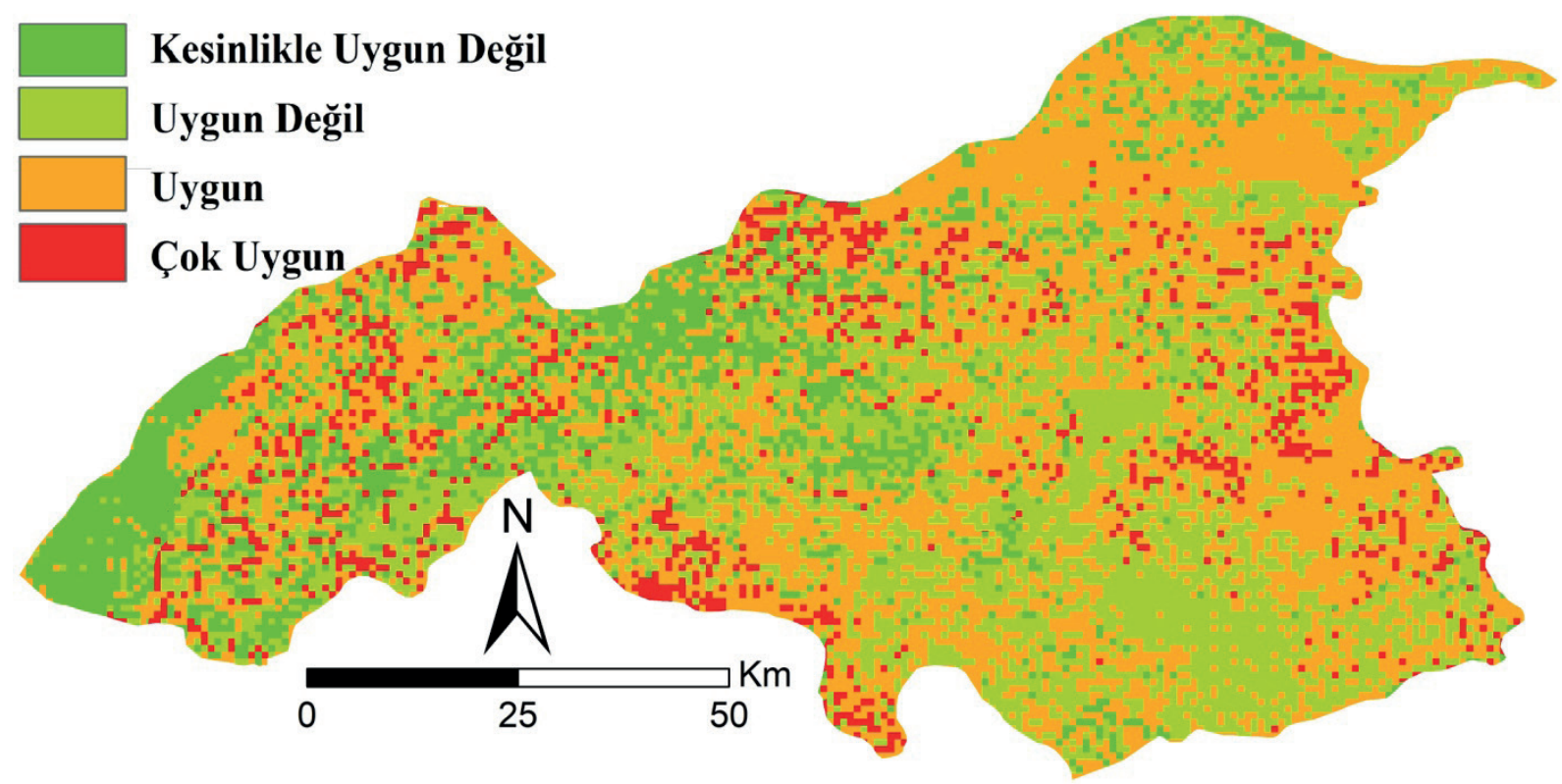

Şekil 8: Gaziantep İlinin Güneş Enerjisi Verimlilik Haritası.

Figure 8: Solar energy efficiency map of Gaziantep province.

\section{SONUÇ}

$\mathrm{Bu}$ çalışmada hem ucuz enerji üretimi ve doğru yer seçimi hem de ekolojik zararların en aza indirilmesi amacıyla fiziki ve beşeri çevreye ait parametreler kullanılarak Gaziantep ilinin güneş enerjisi verimlilik haritası oluşturulmuştur. Buna göre enerji ihtiyacı yüksek olan ve gün geçtikçe artan Gaziantep'in, aynı zamanda hem çevreci hem de rezerv sıkıntısı olmayan güneş enerjisi potansiyelinin yüksek olduğu belirlenmiştir.

Alternatif enerji arayışı içerisinde güneş enerjisi, çevreye duyarlı ve sürdürülebilir olması, özellikle bölgesel/ulusal enerji bağımsızlı̆̆ının artması, önemli iş fırsatlarının sağlanması, enerji arzınınçeşitlendirilmesi vegüvenliğiilekırsalelektriklendirmenin hızlandırılması gibi pozitif etkileri nedeniyle en önemli alternatif kaynaktır (Tsoutsos, vd.,2005 s.289). Güneş enerjisi çevresel etkileri minimum seviyede, temiz, yerel ve sürekli bir kaynak olması ayrıca üretilen enerji kaynakları içinde gün geçtikçe maliyetinin azalması gibi sebeplerle son yıllarda daha fazla tercih edilen bir kaynak olmakla birlikte, enerji üretim kapasitesinde mevsimlik (yaz-kış) ve günlük (gece-gündüz) farklılıklar göstermesi gibi bir takım olumsuz özellikler de taşımaktadır. Ayrıca güneş enerjisi santralinin kurulması hem maliyet hem de arazinin işgal edilmesini de beraberinde getirmektedir. Özellikle arazi kullanımında doğru yerin tercih edilmesi ve çevresel zararların en aza indirmesi için saha mutlak suretle belli bir planlamaya tabi tutulmak zorundadır. Bu sebeple üretim için öncelikle kaynak potansiyelinin belirlenmesi ve santralin coğrafi konumunun bilhassa çok iyi analiz edilmesi için fiziki ve beşeri parametrenin bir arada kullanılması gerekmektedir. Dolayısıyla Enerji İşleri Genel Müdürlüğü tarafından, Türkiye için sadece iklimsel kriterlere göre hazırlanan Güneş Enerjisi Potansiyel Atlası (GEPA) yetersiz kalmakta, bu konuda her saha için fiziki, beşeri ve ekonomik tüm faktörlerin de göz önünde bulundurulduğu yerel analiz çalışmalarının yapılması gerekmektedir. Öte yandan, insan yapımı hiçbir projenin çevreye herhangi bir etkiden tamamen kaçınamayacağ da bilinmelidir (Tsoutsos, vd.,2005 s.296). Yenilenebilir enerji kaynakları dahi çevresel bir takım sorunlar yaratabilirler. $\mathrm{Bu}$ bağlamda etkisi en az olan kaynak güneş enerjisi olsa dahi örneğin, santral kurulumunda geniş bir alana ihtiyaç duyulması arazi kullanımında vasıf değişikliğine yol açabilmektedir. Ekolojik ve arkeolojik hassas bölgelerin kurulum sahalarında yer almamasına dikkat edilmelidir. Santral kurulumu için çorak alanlar, eski maden ve sanayi sahaları gibi atıl arazilerin değerlendirilmesi bozulmuş arazilerin geri kazanılmasını da sağlayacaktır. Dolayısıyla olası planlamalarda çevre etki değerlendirme (ÇED) büyük önem arz etmektedir. Ayrıca, küresel iklim değişiminin şiddet, frekans ve alansal bakımdan seçilen sahanın iklim parametrelerinde olası değişimlere yol açması güneş enerji potansiyelinde de farklılıklar yaratabilecektir. $\mathrm{Bu}$ nedenle iklim değişiminin etkilerinin bu tür çalışmalarda ayrıca ortaya konulmasına ihtiyaç vardır.

Türkiye'de oldukça önemli bir potansiyeli olan güneş enerjisinin konvansiyonel santralleri ikame etmesi gerekirken, güneş enerjisinden elektrik elde etme maliyetlerinin oldukça 
yüksek olması yenilenebilir olan bu enerji kaynağının ticari şekilde kullanmasını kısıtlayan en önemli nedenlerden biridir (Yılmaz, 2012). Kurulum ve iletim altyapı maliyetinin yüksek olmas1, PV ekipmanlarının yerli imalat kapasitesinin yetersiz olması ve bu bağlamda ithalat giderlerini artırması güneş enerjisinin önündeki en önemli engeldir. Yenilenebilir Enerji Kaynakları (YEK) kanunu iyileştirilmiş teşvik mekanizmalarının uygulanması ve yerli imalatın desteklenmesi potansiyelin kullanımını artırma yönünde önem arz etmektedir.

Finansal Destek: Yazarlar bu çalışma için finansal destek almamışlardır.

\section{KAYNAKLAR}

Alami Merrouni, A., Elwali Elalaoui, F., Mezrhab, A., Mezrhab, A. and Ghennioui, A. (2018). Large scale PV sites selection by combining GIS and analytical hierarchy process. case study: Eastern Morocco. Renewable Energy(119), 863-873.

Akova, İ. (2003). "Dünya Enerji Sorunu ve Yenilenebilir Enerji Kaynaklarının Kullanımı”, İstanbul Üniversitesi Coğrafya Dergisi, Say1:11, Sayfa: 47-73, İstanbul.

Aydın, N. (2009). GIS-based site selection approach for wind and solar energy systems: a case study from western turkey. Ankara.: ODTÜ Fen Bilimleri Enstitüsü, Yayımlanmamış Yüksek Lisans Tezi.

Boysen, L. R., Brovkin, V., Arora, V. K., Cadule, P., Noblet-Ducoudre, Kato, E., ... Gayler, V. (2014). Global and regional effects of landuse change on climate in 21 st century simulations with interactive carbon cycle. Earth System Dynamics(5), 309-319.

Cebeci, S. (2017). Türkiye'de güneş enerjisinden elektrik üretim potansiyelinin değerlendirilmesi. Uzmanlık Tezi. TC.Kalkınma Bakanlı̆̆l, Iktisadi Sektörler ve Koordinasyon Genel Müdürlüğü. Erişim adresi: HYPERLINK "http://www.sbb.gov.tr/wp-content/ uploads/2018/11/Seda-Cebeci.pdf” http://www.sbb.gov.tr/wpcontent/uploads/2018/11/Seda-Cebeci.pdf

Cronin, J., Anandarajah, G. and Dessens, O. (2018). Climate change impacts on the energy system:a review of trends and gaps. Climatic Change (151), 79-93.

Çarkıt,T.,(2016). PV Panellerin Yapıs1 ve Panellerden Elektrik Üretimine Sıcaklığın Etkisi, ElektrikMüdendisliği Dergisi,TMMOB, Temmuz S: 457

Dale, V. H., Efroymson, R. A. and Kline, K. L. (2011). The land useclimate change-energy nexus. Landscape Ecology (26), 755-773.

Doorga, J. R., Rughooputh, S. D. and Boojhawon, R. (2019). Multicriteria GIS-based modelling technique for identifying potential solar farm sites: A case study in Mauritius. Renewable Energy (133), 1201-1219.

Energy Information Administration (2019). EIA,Washington, USA., Monthly Energy Review. Retrieved from https://www.eia.gov/ totalenergy/data/monthly/
Enerji İşleri Genel Müdürlüğü (2018). Erişim adresi http://www.yegm. gov.tr/MyCalculator/Default.aspx

Enerji İşleri Genel Müdürlüğü (2019). Enerji-İklim Raporu. Sayı 313, 10 Ocak 2019.Erişim Adresi: https://www.eigm.gov.tr/File/?path=R OOT\%2f4\%2fDocuments\%2fRapor\%2fei-s313-web.pdf

Ekinci, D. ve Sönmez, M. E. (2006). İstanbul konürbasyonunun yeni habitat adacığında CBS tabanlı jeoekoloji planlama analizi. Türk Coğrafya Dergisi(46), 147-167.

Enerji ve Tabi Kaynaklar Bakanlığl (2018). Erişim Adresi: HYPERLINK "https://www.enerji.gov.tr/File/?path=ROOT\%2f1\%2fDocuments \%2fEnerji\%20ve\%20Tabii\%20Kaynaklar\%20G\%c3\%b6r\% c3\%bcn\%c3\%bcm\%c3\%bc\%2fSayi_15.pdf” https://www.enerji. gov.tr/File/?path=ROOT\%2f1\%2fDocuments $\% 2$ fEnerji $\% 20$ ve $\% 20$ Tabii $\% 20$ Kaynaklar\%20G\%c3\%b6r\%c3\%bcn\%c3 $\%$ bcm \%c3\%bc\%2fSayi_15.pdf

Enerji ve Tabi Kaynaklar Bakanlı̆̆ı(2018). Erişim Adresi: https://www. enerji.gov.tr/tr-TR/Sayfalar/Gunes

Enerji ve Tabii Kaynaklar Bakanlığı (2019) Türkiye Elektrik Enerjisi Talep Projeksiyonu Raporu, Erişim Adresi: HYPERLINK "https:// www.enerji.gov.tr/File/?path=ROOT/1/Documents/E\%C4\% B0GM\%20Ana\%20Rapor/T\%C3\%BCrkiye \%20Elektrik\%20 Enerjisi\%20Talep\%20Projeksiyonu\%20Raporu.pdf" https://www. enerji.gov.tr/File/?path=ROOT/1/Documents/E\%C4\%B0GM\% 20Ana\%20Rapor/T\%C3\%BCrkiye\%20Elektrik\%20Enerjisi\%20 Talep\%20Projeksiyonu\%20Raporu.pdf

Erinç, S. (1959). Bölge Planı Nasıl Yapılır? Ístanbul Üniversitesi Coğrafya Enstitüsü Dergisi (10), 36-51.

Fu, Y., Tai, A. P. and Liao, H. (2016). Impacts of historical climate and land cover changes on fine particulate matter (PM2.5) air quality in East Asia between 1980 and 2010. Atmospheric Chemistry and Physics (16), 10369-10383.

Gašparovic, I.and Gašparovic, M. (2019). Determining optimal solar power plant locations based on remote sensing and gis methods: A case study from Croatia. Remote Sensing (11), 1-18.

Güney, Y. ve Turoğlu, H. (2018). Çok ölçütlü karar analizi ile erozyon duyarlılık çalışmalarında erozyon yüzeyleri envanter verisinin kullanımı: Selendi Çayı Havzası Örneği. Coğrafi Bilimler Dergisi, $16(1), 105-119$.

Kaiser, P., Unde, R. B., Kern, C.and Jess, A. (2013). Production of liquid hydrocarbons with co2as carbon source based on reverse water-gasshift and fischer-tropsch synthesis. Chemie Ingenieur Technik, 85 (4), 489-499.

Kazakis, N., Kougias, I., and Patsialis, T. (2015). Assessment of flood hazard areas at a regional scale using an index-based approach and analytical hierarchy process: Application in Rhodope-Evros region, Greece. Science of the Total Environment,538, 555-563.

Keçel, S, Yavuzcan,H. (2008). Türkiye'de Bölgesel Sıcaklık Değişimlerinin Güneş Panellerinin Verimliliğine Etkisi, Gazi Üniversitesi Endüstriyel Sanatlar Ĕ̈itim Fakültesi Dergisi Sayı: 22, 12-20.

Kottek, M. (2006). World Map of the Köppen-Geiger climate classification updated. Meteorologische Zeitschrift, Vol. 15, No. 3, 259-263. 
Kumbur, H., Özer, Z., Özsoy, H.ve Avc1, E. (2015). Türkiye'de geleneksel ve yenilenebilir enerji kaynaklarının potansiyeli ve çevresel etkilerinin karşılaştırılması. III. Yenilenebilir Enerji Sempozyumu. Mersin, Türkiye. Erişim adresi: HYPERLINK "http:// www.emo.org.tr/ekler/3f445b0ff5a783e_ek.pdf” http://www.emo. org.tr/ekler/3f445b0ff5a783e_ek.pdf

Mcleish, E. (2013). Dünya Sorunlarl, Enerji Krizi, Bugünün Dünyasına Bakış. Ankara: Tubitak Popüler Bilim Kitapları.

Mpandeli, S., Naidoo, D., Mabhaudhi, T., Nhemachena, C., Nhamo, L., Liphadzi, S., . . . Modi, A. T. (2018). Climate Change Adaptation through the Water-Energy-Food Nexus in Southern Africa. International Journal of Environmental Research and Public Health, 15 (10), 1-19.

Özdemir, M. S. and Saaty, T. L. (2006). The unknown in decision making what to do about it. European Journal of Operational Reserarch (174), 349-359.

Özgür, E. (2018). Güneş Enerjisi. O. Türkyılmaz ve O. Aytaç içinde, Türkiye'nin Enerji Görünümü (s. 349-382). Ankara: MMO yayinlart.

Renewable Energy Policy (2018). REN21 Renewables 2018 global status report. Retrieved from: https://www.ren21.net/gsr-2019/ chapters/chapter_01/chapter_01/

Saaty, T. L. (1990). How to Make a Decision: The analytic hierarchy process. European Journal of Operation Research (48), 9-26.

Saaty, T. L. (2008). Decision making with the analytic hierarchy process. Int. J. Services Sciences, 1(1), 83-98.
Sánchez-Lozano, J. M., Teruel-Solano, J., Soto-Elvira, P. L., and García-Cascales, M. S. (2013). Geographical information systems (g1s) and multi-criteria decision making (mcdm) methods for the evaluation of solar farms locations:case study in south-eastern Spain. Renewable and Sustainable Energy Reviews (24), 544-556.

The International Renewable Energy Agency (IRENA). (2018). Retrieved from https:/www.irena.org/solar

Tol, R. S. (2018). The economic impacts of climate change. Review of Environmental Economics and Policy, 12 (1), 4-25.

Tsoutsos, T., Frnatzeskaka,N. and Gekas, V. (2005) Environmental impacts from the solar energy technologies. Energy Policy, 33 (3), pp. 289-296

Uyan, M. (2013). GIS-based solar farms site selection using analytic hierarchy process (AHP) in Karapinar region, Konya/Turkey. Renewable and Sustainable Energy Reviews(28), 11-17.

Uyan, M. (2017). Güneş enerjisi santrali kurulabilecek alanların AHP yöntemi kullanılarak CBS destekli haritalanması. Pamukkale Üniversitesi Mühendislik Bilimleri Dergisi, 23(4), 343-351.

Ünal, Ö. F. (2012). Performans değerlemede analitik hiyerarşi prosesi (AHP) uygulamaları. Sosyal Bilimler Araştırmaları Dergisi(I), $37-$ 55 .

Wind, Y., \& Saaty, T. L. (1980). Marketing application of the analytic hierarchy process. Management Science, 26 (7), 641-658.

Yılmaz, M. (2012). “Türkiye'nin Enerji Potansiyeli ve Yenilenebilir Enerji Kaynaklarının Elektrik Enerjisi Üretimi Açısından Önemi," Ankara Üniversitesi Çevre Bilimleri Dergisi, say1 4 (2), s. 33-54. 